\title{
Expression and Functional Roles of Kv7/KCNQ/M-Channels in Rat Medial Entorhinal Cortex Layer II Stellate Cells
}

\author{
Maximiliano Jose Nigro, Pedro Mateos-Aparicio, and Johan F. Storm \\ Department of Physiology at the Institute of Basal Medical Sciences, University of Oslo, 0317 Oslo, Norway
}

\begin{abstract}
The medial entorhinal cortex (MEC) is important for spatial navigation and memory. Stellate cells (SCs) of MEC layer II provide major input to the hippocampus, and are thought to be the neuronal correlate of the grid cells. Their electrophysiological properties have been used to explain grid field formation. However, little is known about the functional roles of potassium channels in SCs. M-current is a slowly activating potassium current, active at subthreshold potentials. Although some studies have suggested that Kv7/M-channels may affect subthreshold resonance in SCs, others have found no Kv7/M-current in these cells, so the expression and roles of Kv7/M-channels in SCs are still debated. Using whole-cell voltage-clamp, we have identified a typical M-current with pharmacological properties characteristic of Kv7/M-channels in rat MEC SCs. Current-clamp experiments showed that the specific Kv7/M-channel blocker XE991 increased SCs excitability, and reduced spike frequency adaptation. Our results demonstrate that Kv7/M-channels are expressed in SCs and contribute substantially to regulation of excitability in these cells.
\end{abstract}

\section{Introduction}

Stellate cells (SCs) in layer II of the medial entorhinal cortex (MEC) are thought to be the neuronal correlate of grid cells (Hafting et al., 2005). The intrinsic properties of SCs strongly correlate with the properties of grid cells recorded in vivo (Giocomo et al., 2007; Garden et al., 2008). Previous research on SCs mostly focused on their subthreshold behavior, which is dominated by hyperpolarization-activated cation (HCN) channels (Dickson et al., 2000; Nolan et al., 2007), but little is known about the functions of potassium channels in these cells. In hippocampal pyramidal neurons, Kv7/M-channels underlie several electrophysiological features, including medium afterhyperpolarization (mAHP), excitability control, spike frequency adaptation (SFA), and subthreshold resonance (Madison and Nicoll, 1984; Storm, 1989; Hu et al., 2002; Gu et al., 2005). All those features are expressed by SCs and some have been proposed to contribute to grid field formation (Alonso and Klink, 1993; Giocomo et al., 2007; Garden et al., 2008; Navratilova et al., 2012). However, different studies have come to highly divergent conclusions about the expression and functional roles of $\mathrm{Kv} 7 / \mathrm{M}$ channels in the SCs. For instance, Heys et al. (2010) proposed that Kv7/M-channels might participate in the subthreshold resonance of SCs, and a previous study suggested that these channels regu-

\footnotetext{
Received Sept. 27, 2013; revised April 1, 2014; accepted April 4, 2014.

Author contributions: M.J.N. and J.F.S. designed research; M.J.N. and P.M.-A. performed research; M.J.N. and P.M.-A. analyzed data; M.J.N., P.M.-A., and J.F.S. wrote the paper.

This research was supported by the Norwegian Research Council. We thank Dr Ricardo Murphy and Christoph Hönigsperger for helpful comments on the paper.

The authors declare no competing financial interests.

Correspondence should be addressed to Dr Johan F. Storm, Department of Physiology at the Institute of Basal Medical Sciences, University of 0slo, Post Box 1103 Blindern, 0317 Oslo, Norway. E-mail: j.s.storm@medisin.uio.no.

M. J. Nigro's present address: Department of Physiology, Feinberg School of Medicine, Northwestern University, 303 East Chicago Avenue, Chicago, IL 60611.

DOI:10.1523/JNEUROSCI.4153-13.2014

Copyright $\odot 2014$ the authors $\quad 0270-6474 / 14 / 346807-06 \$ 15.00 / 0$
}

late the afterdepolarization following a spike (Yoshida and Alonso, 2007), but two recent papers reported contradictory findings. One concluded that SCs do not express M-current (Heys et al., 2012), whereas the other reported that Kv7/Mchannels might be involved in subthreshold resonance but not in excitability control (Boehlen et al., 2013). The principal aim of our study was to determine whether SCs express functional Kv7/ M-channels. Using voltage-clamp combined with pharmacology, we were able to unequivocally identify a Kv7-mediated M-current of significant amplitude in SCs, and current-clamp experiments revealed that $I_{\mathrm{M}}$ contributes substantially to regulation of excitability in these neurons. The main results of this study were presented in abstract form (Nigro and Storm, 2012).

\section{Materials and Methods}

Male Wistar rats (postnatal day, P18-P25) were anesthetized with Suprane before decapitation, according to the experimental procedures approved by the Norwegian Ministry of Agriculture. Sagittal slices (400 $\mu \mathrm{m})$ were cut with a Vibratome 3000 or a Leica VT1200 in ice-cold solution containing the following (in $\mathrm{mM}$ ): sucrose $230, \mathrm{NaHCO}_{3} 25, \mathrm{KCl}$ $1.25, \mathrm{KH}_{2} \mathrm{PO}_{4} 1.25$, glucose $16, \mathrm{MgCl}_{2} 7.0$, and $\mathrm{CaCl}_{2} 1.0$, saturated with $\mathrm{O}_{2} 95 \% / \mathrm{CO}_{2} 5 \%$. The slices were incubated at $30^{\circ} \mathrm{C}$ for $0.5 \mathrm{~h}$ and subsequently stored at room temperature in ACSF containing (in $\mathrm{mm}$ ): $\mathrm{NaCl}$ $125, \mathrm{KCl} 1.25, \mathrm{KH}_{2} \mathrm{PO}_{4} 1.25, \mathrm{NaHCO}_{3} 25$, glucose $16, \mathrm{MgCl}_{2} 1.0, \mathrm{CaCl}_{2}$ 2.0, saturated with $\mathrm{O}_{2} 95 \% / \mathrm{CO}_{2} 5 \%$. The slices were then transferred to a recording chamber filled with ACSF kept at $34.5 \pm 0.1^{\circ} \mathrm{C}$, mounted on an upright microscope (Olympus). SCs were identified by their laminar position, morphology and electrophysiological behavior (strong sag, subthreshold oscillations, and action potential properties; Alonso and Klink, 1993). Synaptic activity was blocked with $10 \mu \mathrm{M} \mathrm{DNQX-Na}{ }_{2}(6,7-$ dinitroquinoxaline-2,3-dione disodium salt), $50 \mu \mathrm{M}$ DL-APV (DL-2amino-5-phosphonopentanoic acid) and $5 \mu \mathrm{m}$ gabazine. Pipettes were filled with the following solution (in $\mathrm{mm}$ ): K-gluconate $120, \mathrm{KCl} 20$, HEPES 10, phosphocreatine- $\mathrm{Na}_{2}$ 10, ATP-Mg 4, GTP-Na $\mathrm{Na}_{2}$ 0.3, (290 mOsm, $\mathrm{pH}=7.3$ ) giving a pipette resistance of 3.5-6 $\mathrm{M} \Omega$. A measured liquid junction potential of $14 \mathrm{mV}$ was corrected offline. 
A
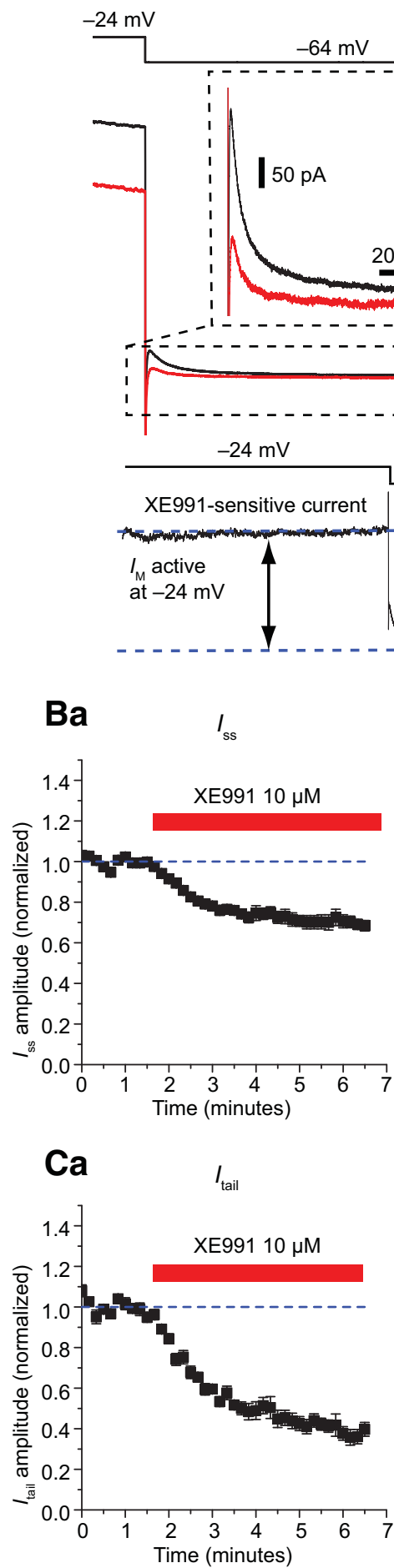

D

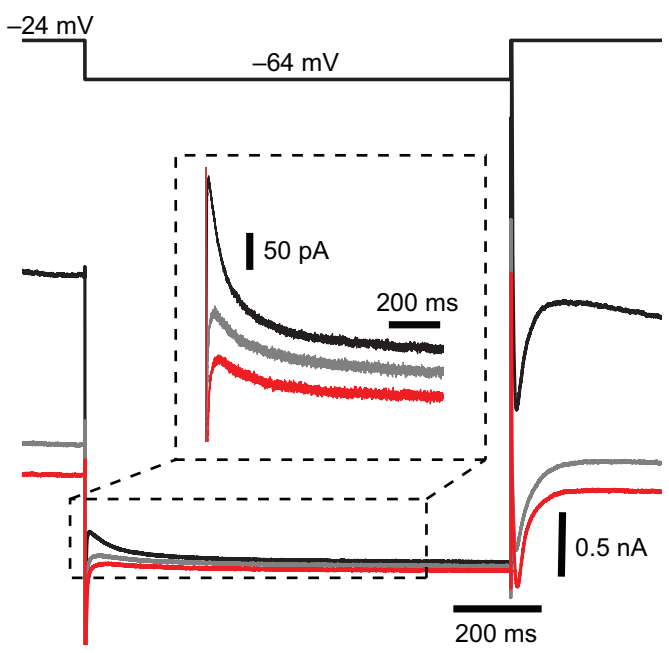

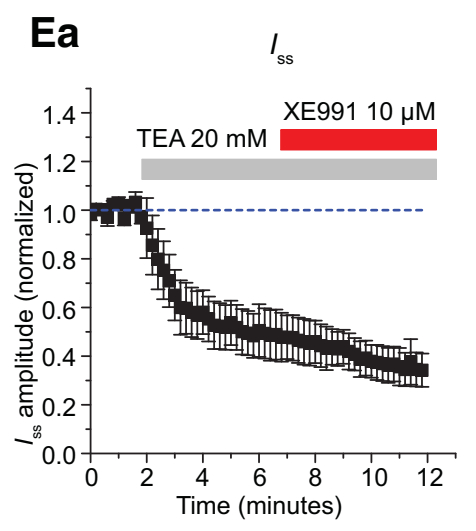

$\mathrm{Fa}$

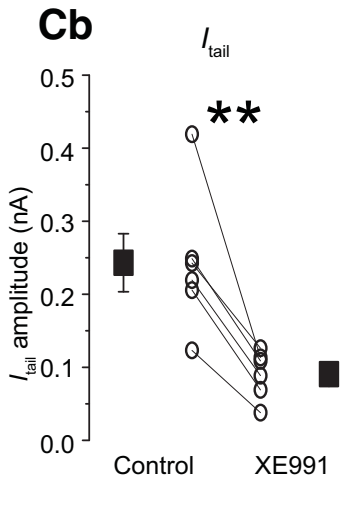

$500 \mathrm{~ms}$
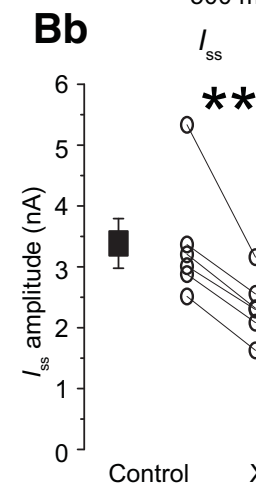

**

Q

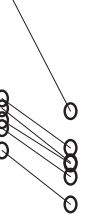

XE991

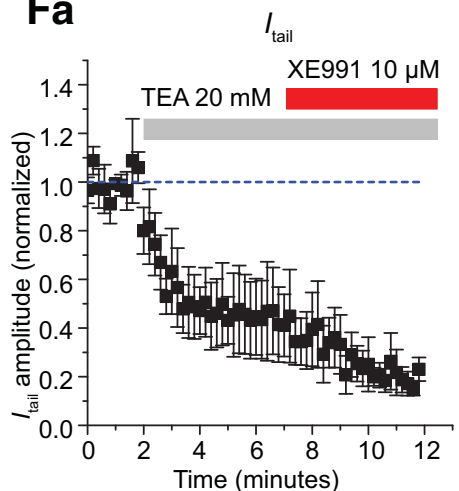

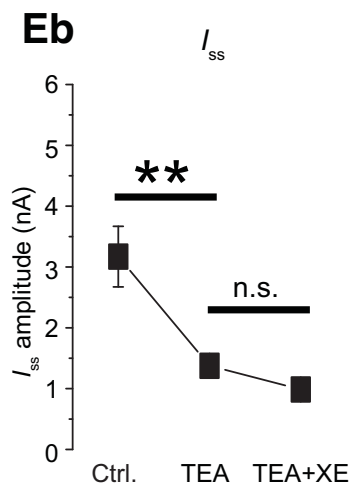

$\mathbf{F b}$

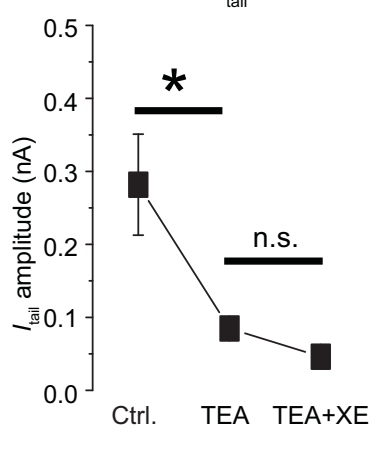

Figure 1. Stellate cells express Kv7-mediated M-current that can be blocked by $10 \mu \mathrm{M}$ XE991. A, Representative whole-cell voltage-clamp recording from a layer II MEC SC, in response to the voltage command protocol indicated by the upper trace. The lower trace shows the tail current evoked by a repolarizing step to $-64 \mathrm{mV}$ in control (black) and after application of $10 \mu \mathrm{M}$ XE991 (red). The bottom shows the XE991-sensitive current obtained by digital subtraction of the red trace (XE991) from the black trace (control). Ba,Time course of the effect of XE991 on the steady-state outward current $\left(I_{\mathrm{ss}}\right)$ during the last $100 \mathrm{~ms}$ of a voltage step to $-24 \mathrm{mV}$ from a holding potential of $-84 \mathrm{mV}$. Bb, Population data showing that XE991 reduced $I_{s s}$; the effect was statistically significant. Ca, Time course of the effect of XE991 on the fast tail current $\left(I_{\text {tail }}\right)$ evoked by a voltage step to $-64 \mathrm{mV}$. $\boldsymbol{C b}$, Population data showing a statistically significant effect of XE991 on $I_{\text {tail }} \cdot \boldsymbol{D}$, Representative recordings showing the effect of $20 \mathrm{~mm}$ TEA on the tail current. Subsequent application of $10 \mu \mathrm{m}$ XE991 had only a minor effect, suggesting that TEA blocks most of the Kv7/M-current in MEC SCs. Ea, Time course of the effect of TEA and XE991 on the $I_{s s}$. Eb, Population data showing that TEA blocked most of the Kv7/M-current activated by the step to $-24 \mathrm{mV}$, whereas the effect of XE991 was not statistically significant. $\mathbf{F a}$, Time course of the effect of TEA and XE991 on the $I_{\text {tail }}$. $\boldsymbol{F b}$, Population data showing that TEA blocked most of the Kv7-mediated tail current and XE991 had only a minor and not statistically significant effect. 
The ACSF for voltage-clamp contained (in $\mathrm{mm}$ ): $\mathrm{NaCl} 125, \mathrm{KCl} 2.5$, $\mathrm{NaHCO}_{3} 25$, glucose $16, \mathrm{MgCl}_{2} 2.0, \mathrm{CaCl}_{2} 0.8, \mathrm{CdCl}_{2} 0.2$, TTx $1.0 \mu \mathrm{M}$, ZD7288 $10 \mu \mathrm{M}$, 4-aminopyridine 4.0, to block voltage-dependent $\mathrm{Ca}_{\mathrm{v}}$, $\mathrm{Na}_{\mathrm{v}}, \mathrm{HCN}$, and Kvl channels, respectively. Cells were held at $-84 \mathrm{mV}$. A $1 \mathrm{~s}$ step to $-24 \mathrm{mV}$ was applied to activate and inactivate voltagedependent potassium currents, followed by a step $-64 \mathrm{mV}$ for $1 \mathrm{~s}$ (to elicit M-tail current), and a $500 \mathrm{~ms}$ step to $-24 \mathrm{mV}$, before returning to the holding potential. This was repeated every $10 \mathrm{~s}$ for $7 \mathrm{~min}$. The effects of XE991 and TEA were measured during the last $100 \mathrm{~ms}$ of the first step to $-24 \mathrm{mV}\left(I_{\mathrm{ss}}\right)$, and on the fast component of the tail current $\left(I_{\text {tail }}\right)$.

For current-clamp experiments a Dagan BVC 700A or a Multiclamp $700 \mathrm{~A}$ amplifier (Molecular Devices) was used. Voltage-clamp recordings were performed with a Multiclamp 700A or 700B amplifier. The series resistance was compensated by $80-85 \%$. Data obtained with a series resistance $>20 \mathrm{M} \Omega$ (voltage-clamp) or $>40 \mathrm{M} \Omega$ (current-clamp) were discarded.

Only neurons with a stable resting membrane potential more negative than $-69 \mathrm{mV}$ and action potential amplitude $>80 \mathrm{mV}$ were accepted for recordings. We did not find any correlation between the effects of the drugs applied and the position of the recorded cells along the dorsoventral axis of the MEC.

Data were acquired using pClamp 10.2 on a personal computer connected to the amplifier via a Digidata- 1440 interface (sampling rate: 20 $\mathrm{kHz}$; low-pass filter: $10 \mathrm{kHz}$ in current-clamp; $4 \mathrm{kHz}$ in voltage-clamp), and analyzed with Clampfit 10.2 (all Molecular Devices) and Origin 8.5 (Microcal). Tail currents recorded in voltage-clamp were best fit with a double-exponential function. The amplitude of the fast component was used to monitor the effect of XE991 (Fig. 1C-F).

The cell input resistance $\left(R_{\text {input }}\right)$ was calculated from the voltage response to subthreshold depolarizing current steps according to Ohm's law (Fig. 2A). The effect of XE991 on excitability was evaluated from the number of action potentials (APs) evoked by a current step able to elicit from 8 to 12 APs in control conditions. The SFA was quantified from spike trains by calculating an Adaptation Index as $\left(1-\left(F_{\text {last }} / F_{\text {initial }}\right)\right)$, where $F_{\text {last }}$ represents the average frequency of the last two interspike intervals (ISIs), and $F_{\text {initial }}$ is the average frequency of the first three ISIs. Data are presented as mean \pm SEM. Significance: ${ }^{\star} p<0.05,{ }^{* *} p<0.01$, ${ }^{* * *} p<0.001$.

DNQX, DL-APV, TTx-citrate, ZD7288, and XE991 [10,10-bis(4pirinydilmethyl)-9(10H)-antracenone] were obtained from Tocris Bioscence, and retigabine from Alomone Labs. All the remaining chemicals were obtained from Sigma-Aldrich AS and VWR PROLABO International AS.

\section{Results}

To isolate the Kv7/M-current $\left(I_{\mathrm{M}}\right)$, we used whole-cell voltageclamp with a classical M-current protocol (Brown and Adams, 1980), in presence of $\mathrm{Na}^{+}$- and $\mathrm{Ca}^{2+}$-channel blockers, but not Kv7/M-channel blockers (see Materials and Methods). From a holding potential of $-84 \mathrm{mV}$, a $1 \mathrm{~s}$ step to $-24 \mathrm{mV}$ was used to activate $I_{\mathrm{M}}$, while inactivating most other voltage-gated currents. Stepping back to $-64 \mathrm{mV}$ revealed a tail current that decayed with fast $\left(I_{\text {tail }} ; 40.8 \pm 1.8 \mathrm{~ms}\right)$ and slow $(104.7 \pm 12.5 \mathrm{~ms})$ time constants. Application of the Kv7/M-channel blocker XE991 (10 $\mu \mathrm{M})$ strongly reduced both $I_{\text {tail }}(\sim 63 \%$ reduction; Fig. $1 C)$ and $I_{\mathrm{ss}}$ $(\sim 31 \%$ reduction; Fig. $1 B)$. The XE991-sensitive $I_{\mathrm{ss}}$ was $1.04 \pm$ $0.2 \mathrm{nA} ;(n=6)$. The fast and slow XE991-sensitive tail components were $0.26 \pm 0.04 \mathrm{nA}$ and $0.07 \pm 0.01 \mathrm{nA}$, and their time constants were $24.2 \pm 2.6 \mathrm{~ms}$ and $190.2 \pm 16.3 \mathrm{~ms}$, respectively $(n=6)$.

These results strongly suggest that $I_{\text {tail }}$ was mainly due to Kv7/ $\mathrm{M}$-channels and, hence, that functional $\mathrm{Kv} 7 / \mathrm{M}$-channels are expressed in MEC SCs. The tail current remaining in $10 \mu \mathrm{M}$ XE991 may be due to less XE991-sensitive channels with similar kinetics, e.g., containing the less XE991-sensitive subunit Kv7.5, because significant Kv7.5 mRNA was detected in EC L2 (Schroeder et al., 2000).
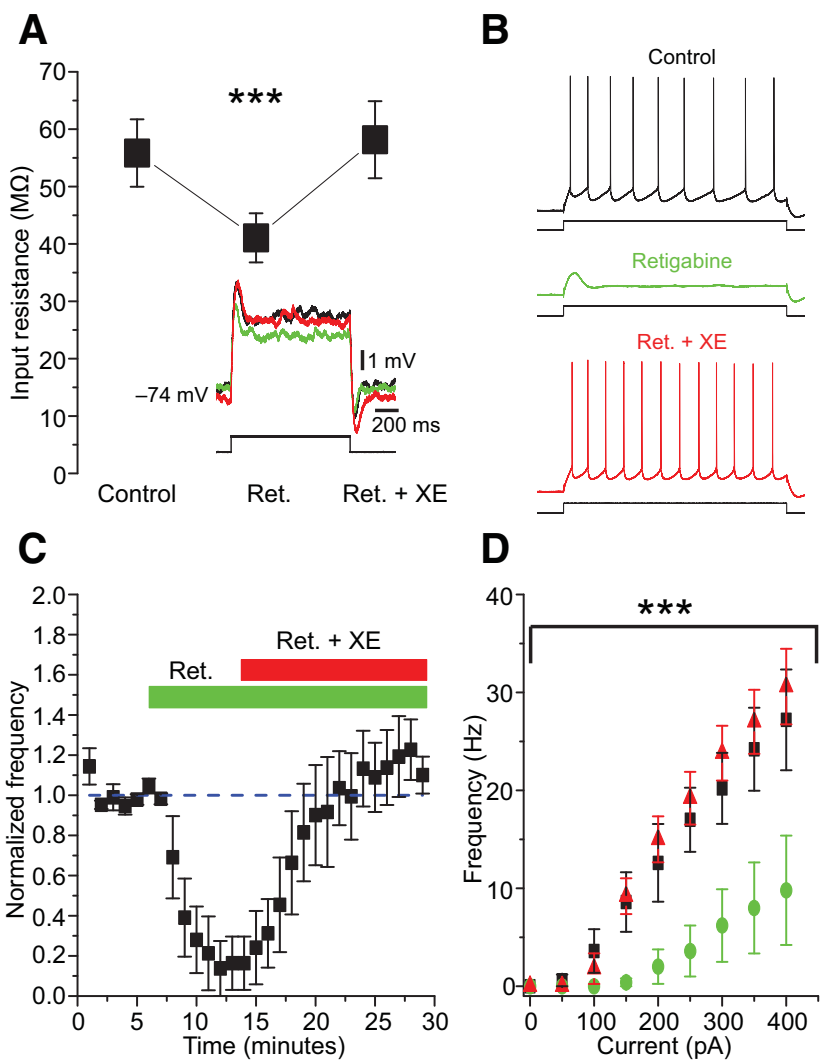

Figure 2. Effects of retigabine showed that MEC SCs express functional Kv7/M-channels. $\boldsymbol{A}$ The Kv7/M-channels agonist retigabine $(10 \mu \mathrm{M})$ decreased the cell input resistance $\left(R_{\text {input }}\right)$ and excitability. Subsequent application of XE991 (10 $\mu \mathrm{m})$ reversed the effects of retigabine $(n=$ 5). Figure $2 A$ shows representative voltage responses to 1-s-long current steps ( $50 \mathrm{pA}$; control, black; retigabine, green; XE991, red). $\boldsymbol{B}$, Representative traces of action potential trains elicited by depolarizing current steps in the three conditions tested. Retigabine strongly reduced the intrinsic excitability and its effects were reversed by application of XE991. C, Time course of the effects of retigabine and XE991. $D$, Effect of retigabine on the average $f / I$ curve $(n=5)$, subsequent application of XE991 restored the cell excitability.

However, a recent study detected no M-current in MEC SCs (Heys et al., 2012). How may this be explained? According to the methods section of that paper, all the experiments were performed in presence of $20 \mathrm{~mm}$ TEA (Heys et al., 2012), which is known to block several M-channel variants (Hadley et al., 2003). Indeed, we found that TEA $(20 \mathrm{~mm})$ reduced the $I_{\text {tail }}$ amplitude by $\sim 65 \%$, from $0.34 \pm 0.06$ to $0.12 \pm 0.03 \mathrm{nA}(p<0.01, n=7$; Fig. $1 D-F)$. TEA also reduced $I_{\text {ss }}$ by $\sim 57 \%$, from $3.17 \pm 0.5 \mathrm{nA}$ to $1.37 \pm 0.1 \mathrm{nA}(p<0.01, n=5)$. Thus, TEA had similar effects as XE991 (Fig. 1A). Subsequent application of $10 \mu \mathrm{M}$ XE991, had no significant effect although the mean $I_{\text {tail }}$ was slightly reduced (Fig. $1 D-F)$. Because TEA occluded most of the XE991 effect, we conclude that TEA and XE991 largely blocked the same current, $I_{\mathrm{M}}$, and that MEC SCs express a TEA-sensitive M-current, like many other cortical neurons (Storm, 1989; Hadley et al., 2003).

Because blockade of other channel types by higher concentrations of XE991 has been reported (Wang et al., 1998; Elmedyb et al., 2007), we wanted another, independent test of the existence of functional Kv7/M-channels in SCs.

To this end we applied the powerful and selective Kv7/Mchannel opener retigabine $(10 \mu \mathrm{M})$ while injecting subthreshold depolarizing current pulses, in current-clamp, to measure $R_{\text {input }}$ (Fig. 2A) from a holding potential of $-74 \mathrm{mV}$ (Fig. $2 B$ ). As shown in Figure $2 A$, retigabine reduced the average somatic $R_{\text {input }}$ of the cells, even at potentials negative to $-70 \mathrm{mV}$ (from $55.8 \pm 5.9 \mathrm{M} \Omega$ 
to $41.1 \pm 4.3 \mathrm{M} \Omega$ ). To test whether the effects of retigabine were really due to its action on Kv7/M-channels, we applied XE991 (10 $\mu \mathrm{M}) 8 \mathrm{~min}$ after the application of retigabine. XE991, in the continued presence of retigabine, reversed the effect of retigabine, and caused an increase in the average $R_{\text {input }}$ slightly beyond the value measured in drug-free medium (Fig. $2 A$ ). The effects of retigabine and XE991 plus retigabine on $R_{\text {input }}$ were statistically significant (one-way repeated-measures ANOVA, $p<0.001$ ).

To test the effects of retigabine on the excitability of SCs, and thus further test for the presence of functional KV7/M-channels, we injected 1-s-long depolarizing current pulses that evoked $8-12$ spikes in control condition. Application of $10 \mu \mathrm{M}$ retigabine strongly reduced the number of APs evoked by the pulses (Fig. $2 B ; n=5 ; p<0.01$, one-way repeated-measures ANOVA). Indeed, after some minutes of retigabine application, four of five cells tested stopped firing APs in response to the pulse (Fig. $2 B$, green trace). Application of $10 \mu \mathrm{M}$ XE991, in the continued presence of retigabine, fully restored the excitability in all the cells tested (Fig. 2B, red trace). Indeed, the average frequency in retigabine plus XE991 became higher than in the control condition ( $n=5$; Fig. $2 C$ ), although the difference did not reach statistical significance. Retigabine reduced the excitability of SCs for a wide range of injected current amplitudes, and the subsequent application of XE991 caused a slight increase of the excitability (Fig. $2 D ; p<0.001$, two-way repeatedmeasures ANOVA).

To test whether Kv7/M-channels regulate the excitability of SCs under normal conditions, we next studied the effects of XE991 alone. Application of $10 \mu \mathrm{M}$ XE991 again significantly increased the $R_{\text {input }}$ calculated from the voltage response to depolarizing current steps (control: $37.4 \pm 2.4 \mathrm{M} \Omega$; XE991: $44.2 \pm$ 3.2 $\mathrm{M} \Omega ; n=30$, paired Student's $t$ test, $p<0.001$ ), but we found no significant change in the resting membrane potential $(n=30$; control: $-73.5 \pm 0.4 \mathrm{mV}$; XE991:-73.8 $\pm 0.6 \mathrm{mV})$.

Yoshida and Alonso (2007) found that Kv7/M-current does not seem to regulate excitability in MEC SCs. Thus, injecting 1-s-long depolarizing current pulses that evoked a minimum of 8 APs (range, 8-15), they found that the Kv7/M-channel blocker linopirdine $(10 \mu \mathrm{M})$ did not affect the number of evoked APs (Yoshida and Alonso, 2007, their Figs. 6A and $1 A$ ). Because their results seem to contradict our conclusion that there is a significant amount of $\mathrm{Kv} 7 / \mathrm{M}$-current in SCs, we wanted to re-examine this issue under similar conditions as those used by Yoshida and Alonso (2007).Thus, we applied 1-s-long current pulses that evoked 8-12 APs in normal medium $(n=10)$ and applied $10 \mu \mathrm{M}$ XE991, while holding the cells at $-74 \mathrm{mV}$ (Fig. 3A). We found that the number of evoked APs clearly increased after XE991 application, by an average of $\sim 47 \%$ and with a convincing time course (Fig. 3B). The effect was statistically significant (Fig. 3B; $n=10$; paired Student's $t$ test, $p<0.001$ ).

We also tested the effects of XE991 on the relation between spike frequency and stimulus current ( $f / I$ curve) of SCs (Fig. $3 B c$ ), by injecting 1-s-long depolarizing current pulses of increasing amplitude with intervals of $0.05 \mathrm{nA}$, before and after bathapplication of $10 \mu \mathrm{M}$ XE991. The application increased the average number of APs (measured $\sim 20$ min after the onset of XE991 application). A two-way repeated-measures ANOVA revealed that there was a significant difference between the $f / I$ curves before and during XE991 application $(n=10, p<0.01)$.

Because Kv7/M-channels exert excitability control of SCs, we expected that they should also contribute to SFA, which is a typical feature of MEC SCs (Alonso and Klink, 1993). We measured the adaptation index (see Materials and Methods) in traces se- lected from the $f / I$ experiments, choosing only those traces with a very similar $F_{\text {initial }}$ before and after XE991 to obtain a similar activation of the sAHP (Fig. 3C). With this type of comparison, we found that the adaptation index significantly decreased from $0.65 \pm 0.06$ to $0.58 \pm 0.06$ (Fig. $3 D ; n=16 ; p<0.001$, paired Student's $t$ test), thus unmasking the role of Kv7/M-channels in SFA.

\section{Discussion}

The main aim of this study was to determine whether a Kv7/Mcurrent exists in MEC layer II SCs, because of the functional importance of this issue and several previous, conflicting results. Our data seem to show clearly, for the first time to our knowledge, that SCs express a Kv7/M-current. Thus, our somatic voltage-clamp recordings revealed a voltage-gated outward current with the characteristics of a typical neuronal Kv7/M-current: slow deactivation kinetics with time constants $>20 \mathrm{~ms}$, and sensitivity to the specific blocker XE991. These findings agree with previous histochemical findings of Kv7/KCNQ mRNA in rodent MEC: KCNQ5 in rat MEC (Schroeder et al., 2000); KCNQ3 and KCNQ2 mRNA in mouse MEC layer II, KCNQ2 seeming lower than KCNQ3 (Allen Brain Atlas).

Our voltage-clamp results were consistently confirmed by our current-clamp tests. In particular, the Kv7/M-channels agonist retigabine profoundly suppressed SCs excitability, reducing $R_{\text {input }}$ and abolishing firing. Moreover, subsequent application of XE991 reversed the effect of retigabine, demonstrating that its effects were mediated by Kv7/M-channels. Except for certain important differences (see below) these results largely agree with and extend the findings of a recent, independent report (Boehlen et al., 2013) that appeared in parallel with our results, and with some previous retigabine results (Hetka et al., 1999).

Further exploring the functions of Kv7/M-channels in SCs, we found that Kv7/M-channels have a substantial impact on excitability at depolarized membrane potentials, in particular near and above the spike threshold, whereas the effect was weaker near the resting membrane potential $(\sim-74 \mathrm{mV})$. This difference reflects the characteristic voltage dependence of these channels.

The Kv7/M-channel blocker XE991 strongly increased the firing frequency of SCs, demonstrating that these channels represent a brake during repetitive firing, as in many other neuron types (Brown and Passmore, 2009). We also demonstrate that M-channels contribute specifically to SFA, reflecting the slow activation of this channel type, as previously shown in other neuron types (Brown and Adams, 1980; Madison and Nicoll, 1984; Gu et al., 2005).

Several factors may explain why our results differ from previous studies. Thus, M-current can relatively easily be lost through wash-out, linopiridine is a weaker M-current blocker than XE991 (Wang et al., 1998), and lack of time plots may obscure drug effects. Yoshida and Alonso (2007) also recorded at $30^{\circ} \mathrm{C}$ (vs our $34^{\circ} \mathrm{C}$ ) and $\mathrm{M}$-current depends on temperature (Hu et al., 2002). A recent report concluded that XE991 had no effect on tail currents evoked by steps to $-60 \mathrm{mV}$ from a holding potential of -35 $\mathrm{mV}$, suggesting that SCs do not express Kv7/M-current, although similar temperature and rats of similar age were used (Heys and Hasselmo, 2012). However, if $20 \mathrm{~mm}$ TEA were used, as indicated by their methods description, $I_{M}$ would already be largely blocked. Thus, we found that the $I_{\mathrm{M}}$ of MEC SCs was readily blocked by TEA (Fig. $1 D-F$ ). This also suggests that $I_{\mathrm{M}}$ in SCs is largely mediated by the TEA-sensitive subunits Kv7.2 and/or Kv7.3, rather than only by Kv7.5 subunits, which are considerably more resistant to both TEA and XE991 (Schroeder et al., 
A

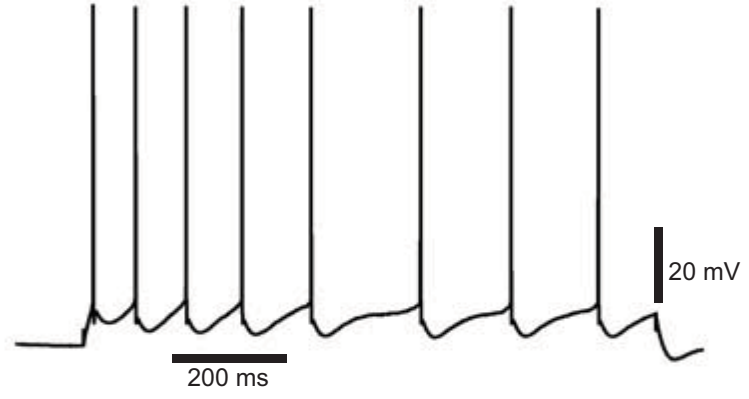

$\mathrm{Ba}$

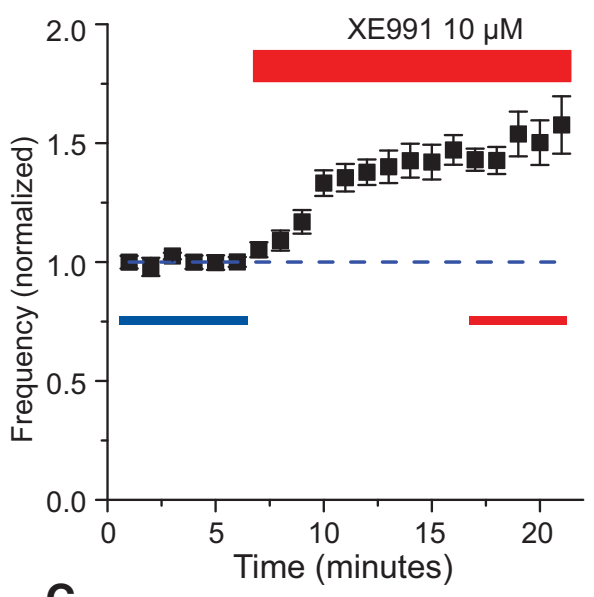

First three ISIs

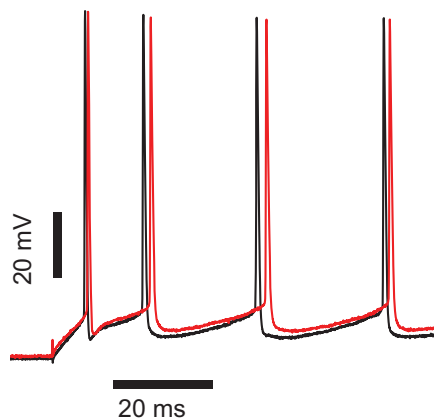

C
$\mathrm{Bb}$

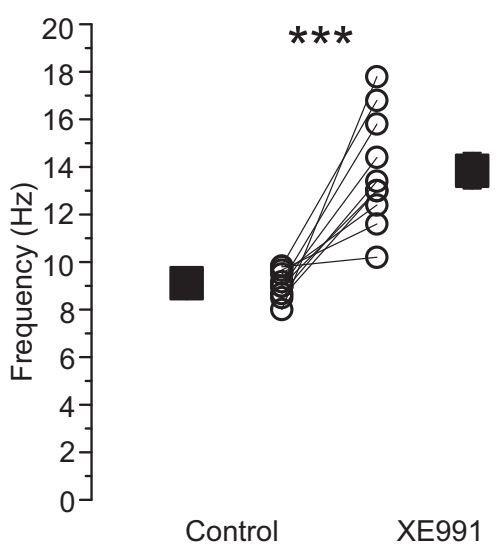

Last two ISIs

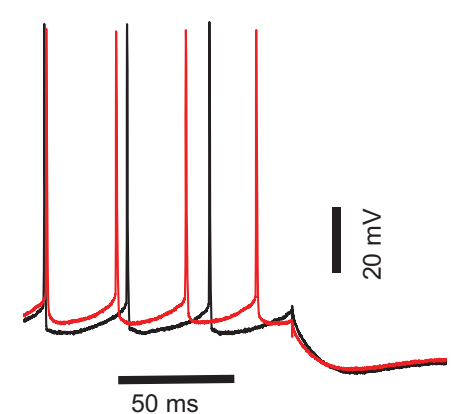

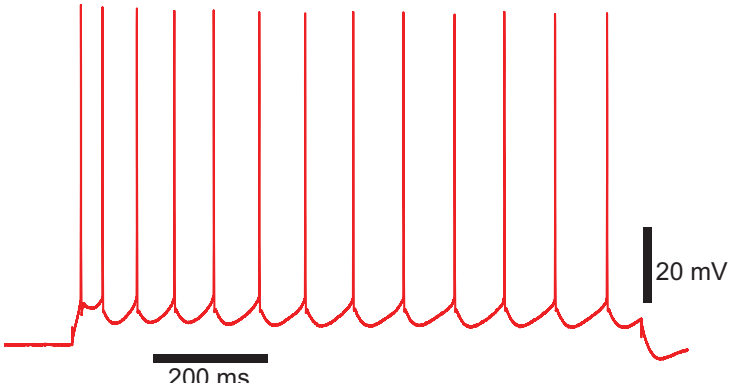

Bc
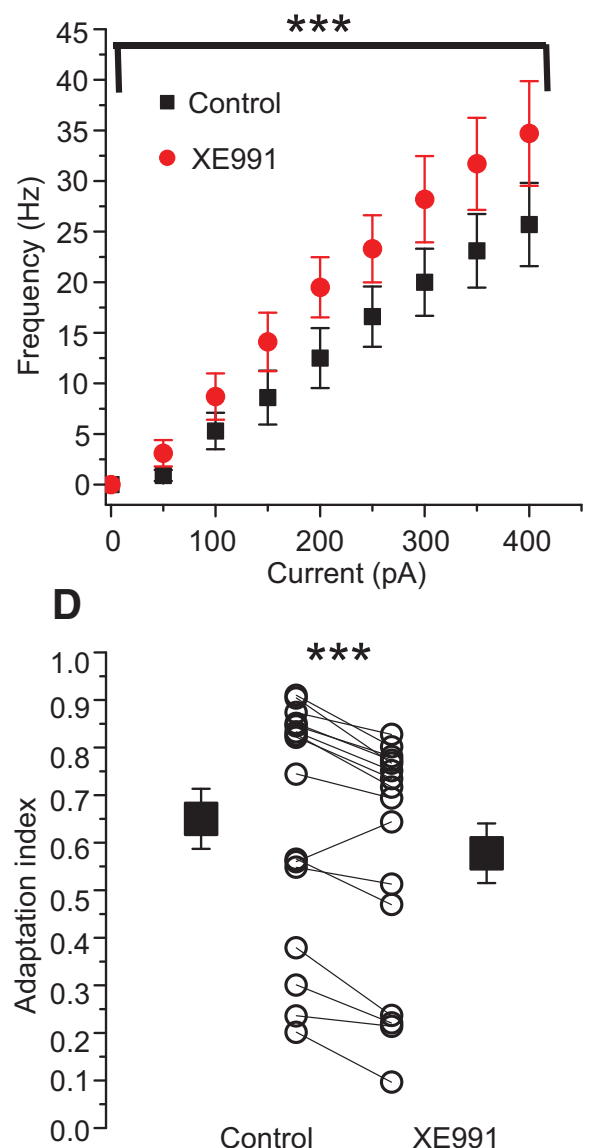

Figure 3. Kv7/M-channels contribute to excitability control in MEC SCS. A, Representative traces of spike trains in response to 1-s-long depolarizing current steps of $150 \mathrm{pA}$ in normal medium (black) and after application of $10 \mu \mathrm{M}$ XE991 (red). B. The mean spike frequency during the 1-s-long current steps was increased by XE991 (a) and the change was statistically significant (b). The effect of XE991 on the intrinsic excitability was evident throughout the whole range of stimulus intensities tested (BC). C, Representative traces showing an expanded view of the first three (left) and last two (right) interspike intervals (ISIs) from the traces with a similar initial spike frequency $\left(F_{\text {initial }}\right)$ in control $(56.2 \mathrm{~Hz})$ and XE991 (54.2 Hz). D, XE991 significantly reduced the adaptation index.

2000; Hadley et al., 2003). However, the remaining TEA- and XE991-resistant tail current in Figure $1 A-D$, might well be due to Kv7.5 channels, because the Kv7.5 subunit is expressed in MEC (Schroeder et al., 2000). In addition, although the pipette solution of Heys and Hasselmo (2012) was very similar to ours, their reported junction potential is quite different (5 vs $14 \mathrm{mV}$ ), although our calculations indicate that it should be $13 \mathrm{mV}$. If 13 $\mathrm{mV}$ is correct, their voltage commands would be less depolarized (stepping to -68 from $-43 \mathrm{mV}$ ), which would have reduced the $I_{\mathrm{M}}$ tail current even in absence of TEA.

To our knowledge, the present results give the most complete demonstration of the expression and functional roles of Kv7/Mcurrent in SCs. Kv7/M-channels in the MEC SCs might also be involved in the cholinergic modulation, which is known to be highly important for memory formation (Shalinsky et al., 2002; Magistretti et al., 2004) and spatial navigation (Brandon et al., 2011; Koenig et al., 2011), as well as for Alzheimer's disease and other forms of neurodegeneration and dementia (Dumas and Newhouse, 2011; Schliebs and Arendt, 2011). Furthermore, the dual h-current/M-current mechanisms demonstrated in the MEC SCs, are reminiscent of CA1 pyramidal cells (Storm, 1990; Hu et al., 2002), and may enable differential modulation of theta resonance, $\mathrm{mAHP}$, and excitability in a voltage-dependent manner via different transmitters and signaling cascades. Thus, noradrenergic input from locus coerulus, acting via cAMP, may selectively modulate $I_{\mathrm{h}}$ that dominates at highly negative poten- 
tials (Pedarzani and Storm, 1996; Boehlen et al., 2013), whereas cholinergic input from the medial septum may differentially modulate both $I_{\mathrm{M}}$ and $I_{\mathrm{h}}$, thus covering a wider voltage range (Halliwell and Adams, 1982; Heys and Hasselmo, 2012). By shifting the voltage ranges of $I_{\mathrm{M}}$ and/or $I_{\mathrm{h}}$, these and other modulators may also change the overlap between these currents.

Many different mutations in the KCNQ2 and KCNQ3 genes underlying Kv7/M-channels are known to lead to epilepsy in humans (Jentsch et al., 2000; Cooper and Jan, 2003; Maljevic et al., 2010) Furthermore, epileptic foci are often located in the temporal lobe in general and EC in particular. A recent study showed that $\mathrm{Kv} 7 / \mathrm{M}$-channels might be involved in the hyperexcitable state of stellate cells in an epileptic model based on an increased excitability of the excitatory network in the entorhinal cortex (Kispersky et al., 2010). The authors report that Kv7/M-channels, although little active in the subthreshold range, become pivotal in regulation of the bursting behavior typical of status epilepticus, and that $I_{\mathrm{M}}$ controls the number of spikes per burst (Kispersky et al., 2010).

\section{References}

Alonso A, Klink R (1993) Differential electroresponsiveness of stellate and pyramidal-like cells of medial entorhinal cortex layer II. J Neurophysiol 70:128-143. Medline

Boehlen A, Henneberger C, Heinemann U, Erchova I (2013) Contribution of near-threshold currents to intrinsic oscillatory activity in rat medial entorhinal cortex layer II stellate cells. J Neurophysiol 109:445-463. CrossRef Medline

Brandon MP, Bogaard AR, Libby CP, Connerney MA, Gupta K, Hasselmo ME (2011) Reduction of theta rhythm dissociates grid cell spatial periodicity from directional tuning. Science 332:595-599. CrossRef Medline

Brown DA, Adams PR (1980) Muscarinic suppression of a novel voltagesensitive $\mathrm{K}+$ current in a vertebrate neurone. Nature 283:673-676. CrossRef Medline

Brown DA, Passmore GM (2009) Neural KCNQ (Kv7) channels. Br J Pharmacol 156:1185-1195. CrossRef Medline

Cooper EC, Jan LY (2003) M-channels: neurological diseases, neuromodulation, and drug development. Arch Neurol 60:496-500. CrossRef Medline

Dickson CT, Magistretti J, Shalinsky MH, Fransén E, Hasselmo ME, Alonso A (2000) Properties and role of $I_{\mathrm{h}}$ in the pacing of subthreshold oscillations in entorhinal cortex layer II neurons. J Neurophysiol 83:2562-2579. Medline

Dumas JA, Newhouse PA (2011) The cholinergic hypothesis of cognitive aging revisited again: cholinergic functional compensation. Pharmacol Biochem Behav 99:254-261. CrossRef Medline

Elmedyb P, Calloe K, Schmitt N, Hansen RS, Grunnet M, Olesen SP (2007) Modulation of ERG channels by XE991. Basic Clin Pharmacol Toxicol 100:316-322. CrossRef Medline

Garden DL, Dodson PD, O'Donnell C, White MD, Nolan MF (2008) Tuning of synaptic integration in the medial entorhinal cortex to the organization of grid cell firing fields. Neuron 60:875-889. CrossRef Medline

Giocomo LM, Zilli EA, Fransén E, Hasselmo ME (2007) Temporal frequency of subthreshold oscillations scales with entorhinal grid cell field spacing. Science 315:1719-1722. CrossRef Medline

Gu N, Vervaeke K, Hu H, Storm JF (2005) Kv7/KCNQ/M and HCN/h, but not KCa2/SK channels, contribute to the somatic medium afterhyperpolarization and excitability control in CA1 hippocampal pyramidal cells. J Physiol 566:689-715. CrossRef Medline

Hadley JK, Passmore GM, Tatulian L, Al-Qatari M, Ye F, Wickenden AD, Brown DA (2003) Stoichiometri of expressed KCNQ/KCNQ3 potassium channels and subunit composition of native ganglionic M-channels deduced from block by tetraethylammonium. J Neurosci 23:5012-5019. Medline

Hafting T, Fyhn M, Molden S, Moser MB, Moser EI (2005) Microstructure of a spatial map in the entorhinal cortex. Nature 436:801-806. CrossRef Medline

Halliwell JV, Adams PR (1982) Voltage-clamp analysis of muscarinic excitation in hippocampal neurons. Brain Res 250:71-92. CrossRef Medline

Hetka R, Rundfeldt C, Heinemann U, Schmitz D (1999) Retigabine strongly reduces repetitive firing in rat entorhinal cortex. Eur J Pharmacol 386: 165-171. CrossRef Medline

Heys JG, Hasselmo ME (2012) Neuromodulation of $I$ h in layer II medial entorhinal cortex stellate cells: a voltage-clamp study. J Neurosci 32: 9066-9072. CrossRef Medline

Heys JG, Giocomo LM, Hasselmo ME (2010) Cholinergic modulation of the resonance properties of stellate cells in layer II of medial entorhinal cortex. J Neurophysiol 104:258-270. CrossRef Medline

$\mathrm{Hu} \mathrm{H}$, Vervaeke K, Storm JF (2002) Two forms of electrical resonance at theta frequencies, generated by $\mathrm{M}$-current, h-current and persistent $\mathrm{Na}+$ current in rat hippocampal pyramidal cells. J Physiol 545:783-805. CrossRef Medline

Jentsch TJ, Schroeder BC, Kubisch C, Friedrich T, Stein V (2000) Pathophysiology of KCNQ channels: neonatal epilepsy and progressive deafness. Epilepsia 41:1068-1069. CrossRef Medline

Kispersky T, White JA, Rotstein HG (2010) The mechanism of abrupt transition between theta and hyper-excitable spiking activity in medial entorhinal cortex layer II stellate cells. PloS One 5:e13697. CrossRef Medline

Koenig J, Linder AN, Leutgeb JK, Leutgeb S (2011) The spatial periodicity of grid cells is not sustained during reduced theta oscillations. Science 332: 592-595. CrossRef Medline

Madison DV, Nicoll RA (1984) Control of the repetitive discharge of rat CA 1 pyramidal neurones in vitro. J Physiol 354:319-331. Medline

Magistretti J, Ma L, Shalinsky MH, Lin W, Klink R, Alonso A (2004) Spike patterning by $\mathrm{Ca} 2+$-dependent regulation of a muscarinic cation current in entorhinal cortex layer II neurons. J Neurophysiol 92:1644-1657. CrossRef Medline

Maljevic S, Wuttke TV, Seebohm G, Lerche H (2010) KV7 channelopathies. Pflugers Archiv 460:277-288. CrossRef Medline

Navratilova Z, Giocomo LM, Fellous JM, Hasselmo ME, McNaughton BL (2012) Phase precession and variable spatial scaling in a periodic attractor map model of medial entorhinal grid cells with realistic after-spike dynamics. Hippocampus 22:772-789. CrossRef Medline

Nigro MJ, Storm JF (2012) Kv7 potassium channels control excitability of stellate cells of the medial entorhinal cortex. FENS Abstr 2012:2897.

Nolan MF, Dudman JT, Dodson PD, Santoro B (2007) HCN1 channels control resting and active integrative properties of stellate cells from layer II of the entorhinal cortex. J Neurosci 27:12440-12451. CrossRef Medline

Pedarzani P, Storm JF (1996) Interaction between alpha- and betaadrenergic receptor agonists modulating the slow $\mathrm{Ca}(2+)$-activated $\mathrm{K}+$ current IAHP in hippocampal neurons. Eur J Neurosci 8:2098-2110. CrossRef Medline

Schliebs R, Arendt T (2011) The cholinergic system in aging and neuronal degeneration. Behav Brain Res 221:555-563. CrossRef Medline

Schroeder BC, Hechenberger M, Weinreich F, Kubisch C, Jentsch TJ (2000) KCNQ5, a novel potassium channel broadly expressed in brain, mediates M-type currents. J Biol Chem 275:24089-24095. CrossRef Medline

Shalinsky MH, Magistretti J, Ma L, Alonso AA (2002) Muscarinic activation of a cation current and associated current noise in entorhinal-cortex layer-II neurons. J Neurophysiol 88:1197-1211. Medline

Storm JF (1989) An after-hyperpolarization of medium duration in rat hippocampal pyramidal cells. J Physiol 409:171-190. Medline

Storm JF (1990) Potassium currents in hippocampal pyramidal cells. Prog Brain Res 83:161-187. CrossRef Medline

Wang HS, Pan Z, Shi W, Brown BS, Wymore RS, Cohen IS, Dixon JE, McKinnon D (1998) KCNQ2 and KCNQ3 potassium channel subunits: molecular correlates of the M-channel. Science 282:1890-1893. CrossRef Medline

Yoshida M, Alonso A (2007) Cell-type specific modulation of intrinsic firing properties and subthreshold membrane oscillations by the $\mathrm{M}(\mathrm{Kv} 7)$-current in neurons of the entorhinal cortex. J Neurophysiol 98:2779-2794. CrossRef Medline 